Article

\title{
Ghost City Extraction and Rate Estimation in China Based on NPP-VIIRS Night-Time Light Data
}

\author{
Wei Ge ${ }^{1}$, Hong Yang ${ }^{1,2, *}$, Xiaobo Zhu ${ }^{1}$, Mingguo Ma ${ }^{1, *}$ (D) and Yuli Yang ${ }^{3}$ \\ 1 Chongqing Engineering Research Center for Remote Sensing Big Data Application, School of Geographical \\ Sciences, Southwest University, Chongqing 400715, China; godwin6@email.swu.edu.cn (W.G.); \\ wavelet@email.swu.edu.cn (X.Z.) \\ 2 Department of Geography and Environmental Science, University of Reading, Reading RG6 6AB, UK \\ 3 School of civil engineering, Lanzhou University of Technology, Lanzhou 730050, China; yyl1980111@lut.cn \\ * Correspondence: hongyang@gmail.com (H.Y.); mmg@swu.edu.cn (M.M.); Tel.: +86-23-6825-3912 (M.M.)
}

Received: 3 May 2018; Accepted: 13 June 2018; Published: 15 June 2018

\begin{abstract}
The ghost city phenomenon is a serious problem resulting from the rapid urbanization process in China. Estimation of the ghost city rate (GCR) can provide information about vacant dwellings. This paper developed a methodology to quantitatively evaluate GCR values at the national scale using multi-resource remote sensing data. The Suomi National Polar-Orbiting Partnership-Visible Infrared Imaging Radiometer (NPP-VIIRS) night-time light data and moderate resolution imaging spectroradiometer (MODIS) land cover data were used in the evaluation of the GCR values in China. The average ghost city rate (AGCR) was 35.1\% in China in 2013. Shanghai had the smallest AGCR of $21.7 \%$, while Jilin has the largest AGCR of $47.27 \%$. There is a significant negative correlation between both the provincial AGCR and the per capita disposable income of urban households $(\mathrm{R}=-0.659, p<0.01)$ and the average selling prices of commercial buildings $(\mathrm{R}=-0.637$, $p<0.01)$. In total, 31 ghost cities are mainly concentrated in the economically underdeveloped inland provinces. Ghost city areas are mainly located on the edge of urban built-up areas, and the spatial pattern of ghost city areas changed in different regions. This approach combines statistical data with the distribution of vacant urban areas, which is an effective method to capture ghost city information.
\end{abstract}

Keywords: China; VIIRS night-time light; ghost city; vacant urban area

\section{Introduction}

China has experienced rapid urbanization in the last decades [1]. Between 1978 and 2012, China's urban population increased from 12.9 to $52.6 \%$ [2]. The National Plan on New Urbanization, which was issued in March 2014, is a macroscopic, strategic and fundamental plan in China. This plan elaborates a set of urbanization targets for China to be achieved by 2020, transforming national urbanization into a people-oriented and ecologically friendly new type of urbanization. However, China's rapid urbanization process has produced some serious problems, for example environmental degradation and a waste of resources [3-5]. The ghost city phenomenon is a serious problem, has had severe effects on land use and ecosystems, creating a waste of energy and resources $[4,6]$. To promote the new urbanization process, the Chinese ghost city problem should be resolved.

There are some studies on ghost cities [7,8]. The problem was first reported and named by the western media. In 2010, Time magazine published a group of pictures of Ordos City in Inner Mongolia [9]. Despite many buildings in the city, no lights were lit at night, earning its status as a "ghost city". Since then, China's ghost city problem has been reported frequently in the world's major media outlets. However, the term "ghost city" is not clearly defined. Shepard [10] defined "ghost city" as "a new development that is running at severe under-capacity, a place with drastically fewer 
people and businesses than there is available space for." Moreover, the ghost city in China is not caused by natural or human-caused disasters such as floods, prolonged droughts, pollution, war or nuclear disasters, but caused by the faster expansion of urban land than the growth of the urban population, which results in few or no inhabitants in urban areas. The Chinese ghost city phenomenon is a unique characteristic of China's rapid urbanization [11]. Thus, there lack of similar ghost city cases to Chinese ghost cities, which are caused by the differences between the urban land expansion and urban population growth. In this study, a ghost city is defined as a municipal region where the vacant built-up area phenomenon is most serious (Section 3.3). We extracted the ghost cities using the degree of vacancy.

Some simple extraction methods for Chinese ghost cities have been proposed in previous studies. The Ministry of Housing and Urban Rural Development of the People's Republic of China indicates that the standard urban population density should be $10,000 / \mathrm{km}^{2}$. According to this standard, the standard ranking organization defined one half of the above standard as the ghost city threshold. In 2015, this organization released China's ghost city index list, which includes 50 cities. Chi et al. [12] used location and population data for research into ghost cities. Jin et al. [10] combined news coverage, road data and the Defense Meteorological Satellite Program-Operational Linescan System (DMSP-OLS) stable night-time data to identify China's ghost cities. However, the extraction results for vacant areas in ghost cities lack spatial pattern information. Zheng [11] used the NPP-VIIRS cloud mask product, multi-source land cover data, and population data to identify ghost cities at the county level. However, the temporal resolution of the data was different (2010 and 2013), and the analysis did not take into account the influence of the Chinese Spring Festival. During this period (from January to March), a large portion of the urban population returned to their hometowns, and the ghost city phenomenon appeared in large cities for a short time.

The housing vacancy rate is one of the most important indicators for assessing the health status of urban real estate. The Ministry of Housing and Urban Rural Development of the People's Republic of China issued an urban planning and construction standard indicating that residential land should account for $25-40 \%$ of urban construction. In the urban built-up area, the main land coverage is residential land. In addition, housing is the main type of residential land. However, there are no official statistics on the housing vacancy rate in China. The China Household Finance Survey (CHFS) [13] found that the urban housing vacancy rate was quite high, with a rapid increase from $20.6 \%$ in 2011 to $22.4 \%$ in 2013. Yao et al. [14] studied the Chinese housing vacancy rate with DMSP-OLS stable night-time light data. Chen et al. [15] used NPP-VIIRS night-time light data and high resolution land use data to estimate the housing vacancy rate in the United States with good results. According to international standards, a housing vacancy rate between 5 and $10 \%$ is normal [16], which means that the real estate market can allow house vacancy for some time. Based on the above study, we accepted the hypothesis that a ghost city area is part of an urban built-up area that has a vacancy phenomenon.

Night-time light imagery can be a good representation of human socio-economic activity [17-19]. This imagery is widely used in urbanization monitoring [20], population estimates [21-23], major disaster monitoring $[24,25]$ and ecological assessment [26,27]. Urban light is the main source of land night-time light [25]. The use of night-time light data can be successfully applied to urban expansion studies [26-32]. Therefore, the NPP-VIIRS night-time light and moderate resolution imaging spectroradiometer (MODIS) land cover data were selected for the extraction of China's ghost cities. This study had two main objectives: (1) to develop a methodology for estimating China's ghost city rate; and (2) to obtain the distribution and morphological characteristics of the ghost cities in China.

\section{Materials and Methods}

In this paper, 31 provincial administrative regions and 333 prefecture-level administrative regions in China with different levels of urbanization and socioeconomic development were selected as the study area. 


\subsection{Data}

The night-time light data used in this paper comprise the NPP-VIIRS day and night band (DNB) cloud-free composite imagery, obtained from the National Oceanic and Atmospheric Administration (NOAA) [33]. The NPP-VIIRS DNB cloud-free composite night-time light imagery was post-processed to remove clouds and correct for stray light [34]. These data are monthly composites with a spatial resolution of 15 arc seconds (approximately $462.5 \mathrm{~m}$ ). In this study, the December 2013 NPP-VIIRS DNB night-time light data was selected to extract the urban built-up area. The December night-time light data can reflect the final expansion of urban built-up areas and population distribution in 2013. Compared to another commonly-used stable night-time light dataset, the DMSP-OLS [35-37], the NPP-VIIRS DNB composite imagery has been calibrated in orbit, providing a higher spatial accuracy and solving the brightness saturation problem [34,38]. However, these data contain not only the brightness from urban areas but also abnormal values such as fire points, volcanoes and background noise. Figure 1 shows that the NPP-VIIRS DNB data contains some pixels with negative values, which are caused by data compositing. In addition, the original data also contain some abnormal pixels with extremely large values, a phenomenon associated with highly reflective surfaces. These abnormal values would interfere with the extraction process. Due to the above problems, the original NPP-VIIRS DNB night-time light data had to be corrected.
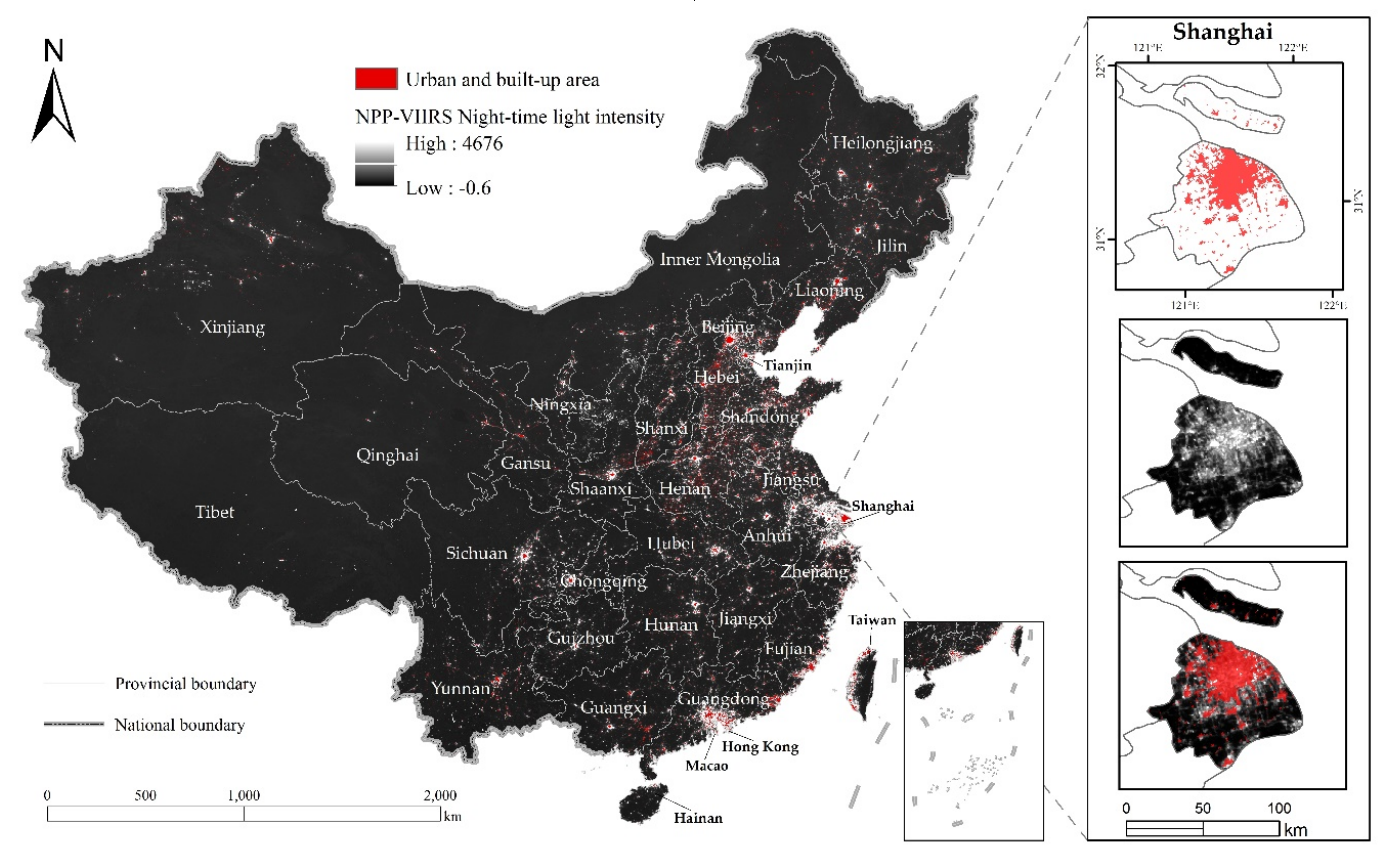

Figure 1. The Suomi National Polar-Orbiting Partnership-Visible Infrared Imaging Radiometer (NPP-VIIRS) imagery night-time light from December 2013 and MODIS land cover type yearly data (MCD12Q1, 2013) urban and built-up areas from 2013, and zoomed in Shanghai.

The combined MODIS land cover type yearly data (MCD12Q1, 2013) were obtained from the United States Geological Survey (USGS) [39]. The MCD12Q1 land cover data have a spatial resolution of $500 \mathrm{~m}$, as shown in Figure 1. It employs the International Geosphere-Biosphere Program (IGBP) classification scheme, and the 13th class comprises urban and built-up areas, indicating land covered by buildings and other man-made structures.

The China Statistical Yearbook is an annual statistical publication compiled by the National Bureau of Statistics in China, including economic and social statistics for the past year. Data on the urban built-up areas in the 31 provincial administrative regions in 2013 [40] were used in this study. 


\subsection{Methods}

In summary, the proposed approach in this study includes five steps (Figure 2). The first step is the remote sensing data preprocessing phase, in which the night-time light (NTL) data and urban and built-up land cover (LCU) data are resampled and re-projected. The second step is to extract the NTL in which the NTL areas are covered by LCU areas. At the same time, the optimal threshold for built-up area extraction is determined by the built-up area statistics and NTL area. The third step is to use the optimal threshold to extract the built-up area in the NTL and NTL $\mathrm{N}_{U}$ data. These two results represent the total built-up (TB) area and the actual urban area with non-vacant built-up (NVB) areas. The last step is to calculate the ghost city rate (GCR) and the average ghost city rate (AGCR) and extract the ghost city.

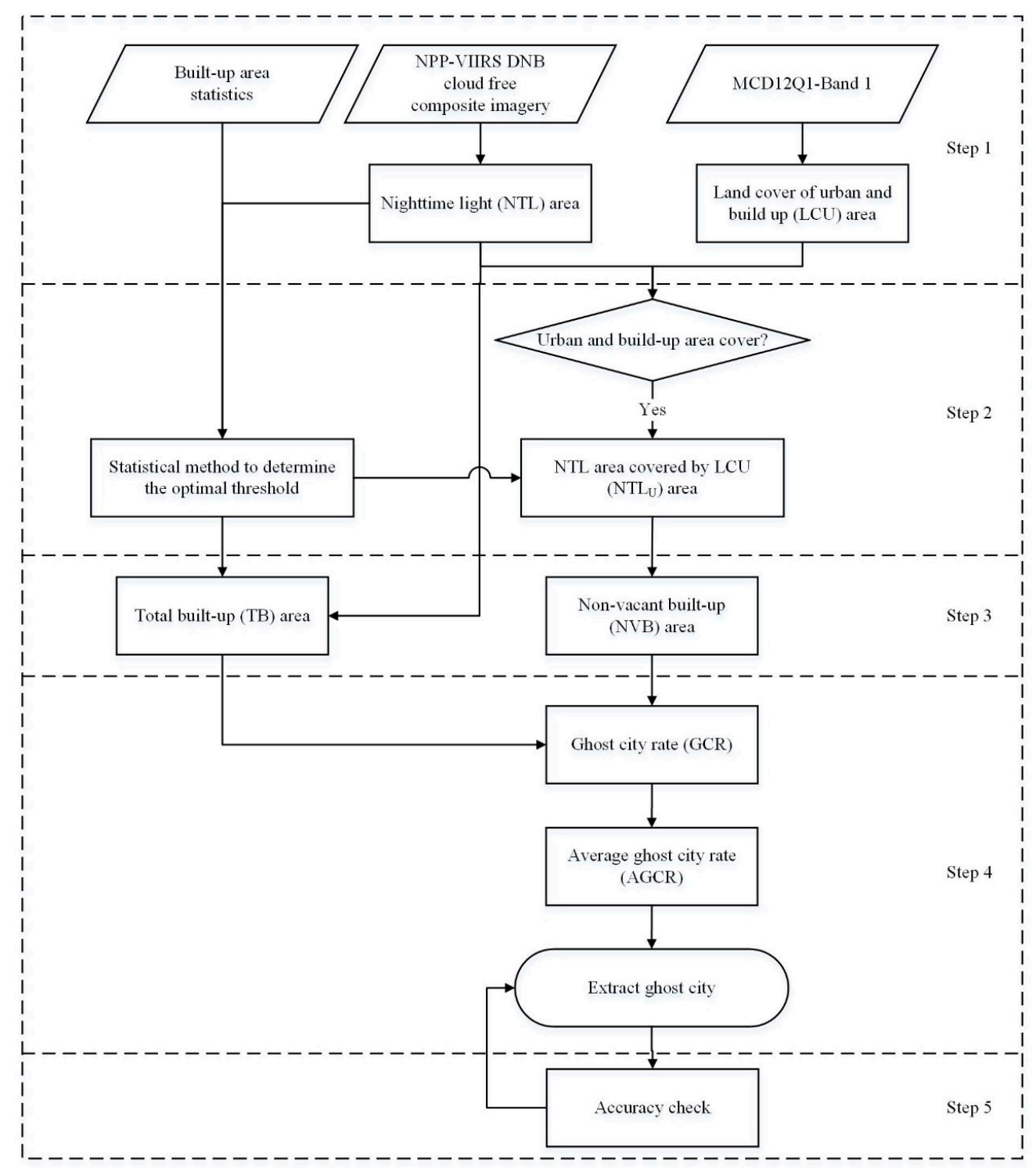

Figure 2. Workflow of the ghost city extraction and rate estimation.

\subsubsection{Night-Time Light and Land Cover Data Preprocessing}

As discussed in Section 2.1, most of the background noise has been removed in the original NPP-VIIRS DNB monthly night-time light imagery, but some abnormal values still remain, including negative values and extremely large values. The negative values are caused by the monthly imagery 
composition process and were regarded as background noise in this study. Thus, we removed this background noise and set the minimum threshold of the NTL imagery to 0 . When correcting the NPP-VIIRS DNB data to extract the built-up area, the maximum brightness of the central urban area can be equal to the maximum threshold of the NTL data [41]. The city with the highest gross domestic product (GDP) in 2013 was Shanghai. As such, we treat Shanghai as the most developed region in China in 2013. Therefore, we use the maximum light intensity $\left(294.349 \mathrm{nWcm}^{-2} \mathrm{sr}^{-1}\right)$ of Shanghai's central built-up area as the maximum threshold for all NTL pixels in China. After this process, the NTL data were in the range of 0-294.349. The land cover data in the MCD12Q1-band1 dataset used the IGBP classification scheme. The 13th land cover class was extracted to retrieve the urban and built-up land cover (LCU) area.

All remote sensing data were projected into the Albers conical equal area projection, and the nearest neighbor algorithm was used to resample to keep the pixel size at $500 \mathrm{~m}$ by $500 \mathrm{~m}$.

\subsubsection{Determine the Built-Up Area Extraction Threshold and Extract NTL $L_{U}$}

The built-up area with night-time light data was extracted in two strategies: imagery segmentation and constructing the feature space [28,42]. The construction of the feature space was generally characterized by combining the night-time light data and the Vegetation Index (VI) or other high spatial resolution remote sensing products, but this method had a high dependence on high-resolution data [43-47]. Considering the large scale in this study, the imagery segmentation method was employed. During the process to extract the urban built-up area based on the night-time light data using the imagery segmentation method, it is important to determine the optimal threshold. Previous studies have developed a number of methods using the optimal threshold techniques [20,27,43,45-48].

The statistical data method was used to determine the light intensity threshold using statistical data on the built-up area that had been published by many government departments due to its relatively high accuracy and reliability [42]. Specifically, the optimal extraction threshold was determined by dichotomies in the night-time light imagery. When the extracted area was closest to the total built-up area data, the optimal extraction threshold was determined [20]. The statistical data method was easy to implement, with a good accuracy and agreement with the NPP-VIIRS night-time data [27].

Moreover, due to large regional differences in the geographical environment and socio-economic development, it was difficult to use a single threshold to extract China's built-up area $[30,48]$. We improved the statistical data method for application in this study using statistical data on the built-up area from 31 provinces and NPP-VIIRS NTL data to calculate the optimal built-up area extraction threshold. The optimal threshold contains both the maximum threshold and minimum threshold in this study. The maximum threshold was the maximum light brightness of the most developed region's central urban area in a province, and the minimum threshold was set using statistical data. This process was iterated by increasing the threshold until the extraction area and the statistical area were the closest. The optimal thresholds for built-up area extraction in China and the 31 provincial administrative regions are listed in Table 1.

Comparing the LCU area with the NTL data indicates that pixels with high fractional settlements generally had high DN values in the NTL imagery. The NTL data were fused with LCU to improve the NVB extraction accuracy and calculate the $\mathrm{NTL}_{U}$, the areas where the NTL areas were covered by LCU areas. It can be extracted using overlay analysis. 
Table 1. Built-up areas and extraction thresholds. The areas of the built-up districts were from the 2013 China Statistical Yearbook. The built-up area extraction thresholds were determined by the statistical data method.

\begin{tabular}{|c|c|c|c|c|c|c|c|c|c|}
\hline ID & Area Name & $\begin{array}{l}\text { Area of Built-Up } \\
\text { Districts }\left(\mathrm{km}^{2}\right)\end{array}$ & $\begin{array}{c}\text { Minimum } \\
\text { Threshold } \\
\left(\mathrm{nWcm} \mathbf{c m}^{-2} \mathrm{sr}^{-1}\right)\end{array}$ & $\begin{array}{c}\text { Maximum } \\
\text { Threshold } \\
\left(\mathrm{nWcm}^{-2} \mathrm{sr}^{-1}\right)\end{array}$ & ID & Area Name & $\begin{array}{c}\text { Area of Built-Up } \\
\text { Districts }\left(\mathrm{km}^{2}\right)\end{array}$ & $\begin{array}{c}\text { Minimum } \\
\text { Threshold } \\
\left(\mathrm{nW} \mathrm{cm}^{-2} \mathrm{sr}^{-1}\right)\end{array}$ & $\begin{array}{c}\text { Maximum } \\
\text { Threshold } \\
\left(\mathrm{nWcm}^{-2} \mathrm{sr}^{-1}\right)\end{array}$ \\
\hline 1 & China & $47,855.28$ & 23.109 & 294.349 & 17 & Jiangsu & 3809.6 & 20.113 & 269.941 \\
\hline 2 & Anhui & 1777.26 & 16.219 & 115.588 & 18 & Jiangxi & 1151.42 & 9.806 & 178.601 \\
\hline 3 & Beijing & 1306.45 & 18.972 & 268.765 & 19 & Jilin & 1344.02 & 10.295 & 218.771 \\
\hline 4 & Chongqing & 1114.92 & 9.92 & 120.46 & 20 & Liaoning & 2386.49 & 12.175 & 282.241 \\
\hline 5 & Fujian & 1263.18 & 22.771 & 124.431 & 21 & Ningxia & 420.69 & 18.401 & 144.833 \\
\hline 6 & Gansu & 726.66 & 13.268 & 139.574 & 22 & Qinghai & 157.36 & 19.065 & 87.485 \\
\hline 7 & Guangdong & 5232.11 & 17.074 & 290.252 & 23 & Shaanxi & 915.02 & 25.896 & 227.707 \\
\hline 8 & Guangxi & 1153.64 & 13.813 & 94.626 & 24 & Shandong & 4187.48 & 11.284 & 261.585 \\
\hline 9 & Guizhou & 695.4 & 18.163 & 137.207 & 25 & Shanghai & 998.75 & 32.321 & 294.349 \\
\hline 10 & Hainan & 296.03 & 19.133 & 84.273 & 26 & Shanxi & 1040.69 & 18.95 & 132.119 \\
\hline 11 & Hebei & 1787.24 & 14.297 & 89.186 & 27 & Sichuan & 2058.11 & 13.901 & 175.011 \\
\hline 12 & Henan & 2289.08 & 13.861 & 291.556 & 28 & Tianjin & 747.26 & 25.855 & 253.574 \\
\hline 13 & Heilongjiang & 1758.38 & 11.747 & 249.615 & 29 & Tibet & 120.29 & 12.659 & 153.719 \\
\hline 14 & Hubei & 2006.71 & 10.862 & 275.906 & 30 & Xinjiang & 1064.87 & 23.108 & 132.259 \\
\hline 15 & Hunan & 1504.95 & 11.794 & 183.506 & 31 & Yunnan & 935.77 & 20.977 & 222.083 \\
\hline 16 & Inner Mongolia & 1206.21 & 14.607 & 196.655 & 32 & Zhejiang & 2399.24 & 18.487 & 293.636 \\
\hline
\end{tabular}




\subsubsection{Extracting Total Built-Up Area and Non-Vacant Built-Up Areas}

Due to the difference in spatial resolution and algorithms, the MCD12Q1 data are very different with respect to the spatial extent of China's built-up areas [11]. In addition, the built-up area from the MCD12Q1 was found to be larger than the official statistical data. Due to of these issues, the LCU data from the MCD12Q1 dataset cannot be used to extract the TB directly. Moreover, the official statistics include the real area of the built-up areas in China. Thus, the statistical data method was used to extract the TB area. More details were mentioned in Section 2.2.2.

The NVB is the area of active human habitation. A large population and frequent socio-economic activities in these areas were indicated by high brightness. Therefore, the NVB satisfies two conditions: it has built-up area land cover, and the light intensity is greater than a certain threshold (the minimum threshold shown in Table 1). The optimal extraction threshold and the NTLU data were used to extract the NVB.

The statistical data on built-up areas determines the quantitative area characteristics, the land cover data determines the spatial distribution characteristics. The NVB data both satisfy the quantitative area characteristics and land cover spatial distribution characteristics. The optimal threshold was used to extract the NTL and NTL $L_{U}$, respectively, and obtain the TB and NVB accordingly. The TB was extracted from the built-up area statistics and NTL data, and the NVB were extracted from the NTL data and optimal threshold.

2.2.4. Calculating the Ghost City Rate and Statistical Analysis

$$
G C R_{i}=1-\frac{N V B_{i}}{T B_{i}}
$$

where $G C R_{i}$ is the vacancy intensity of the $i$ th pixel in a ghost city area. $N V B_{i}$ and $T B_{i}$ are the light intensity values of the $i$ th pixel in the NVB and TB, respectively.

To improve the comparability and visual accuracy of the GCR, the seriousness of the ghost city phenomenon was described in different administrative regions. The GCR imagery was used in this research to generate a new ghost city index with a linearly weighted average algorithm, as expressed in Equation (2). The average ghost city rates (AGCR) at both the provincial and municipal administrative scales were calculated.

$$
\mathrm{AGCR}=\frac{\sum_{i=1}^{n} G C R_{i} f_{i}}{\sum_{i=1}^{n} f_{i}}
$$

where AGCR is the average ghost city rate of the administrative regions; $G C R_{i}$ is the GCR of the $i$ th pixel in an administrative region; $f_{i}$ is the number of the $G C R_{i}$ pixel and $n$ is the $n$th administrative region.

Moreover, to explore the factors influencing ghost cities in China, correlation analyses between the provincial AGCR and several indicators were conducted using SPSS 19 (Statistical Product and Service Solutions, IBM, Armonk, NY, USA).

\subsubsection{Accuracy Check}

He et al. [20] used the statistical method to extract the built-up areas on a provincial scale and had good extraction results (accuracy error less than 3\%). However, considering that the statistical data method is a threshold extraction method, the different scales of the built-up area statistical data may have influenced the extraction results. This difference may affect the extraction results of ghost cities. Due to the above issue, an accuracy check was conducted. The same workflow diagram (Figure 2) of this study was used to estimate the AGCR on a smaller scale using the municipal built-up area statistical data. The five cities were selected as samples to carry out this work. The five sample cities included two capital cities, Hohhot (the capital city of Inner Mongolia) and Xi'an (the capital city of Shaanxi) and three cities with the low municipal AGCRs, Songyuan (a city in Jilin), Hengyang (a city in Hunan), Hanzhong (a city in Shaanxi). The statistical data on the built-up area of the five sample cities were derived from the statistical bulletins and work reports of the local governments in 2013. 


\section{Results}

\subsection{Ghost City Rate Estimation}

After the above five steps, raster imagery of the GCR in China was created (Figure 3). Each pixel represents an area of $0.25 \mathrm{~km}^{2}$, and the pixel value is the proportion of the vacancy, which ranges from 0 to 1 and reflects the seriousness of the ghost city phenomenon.

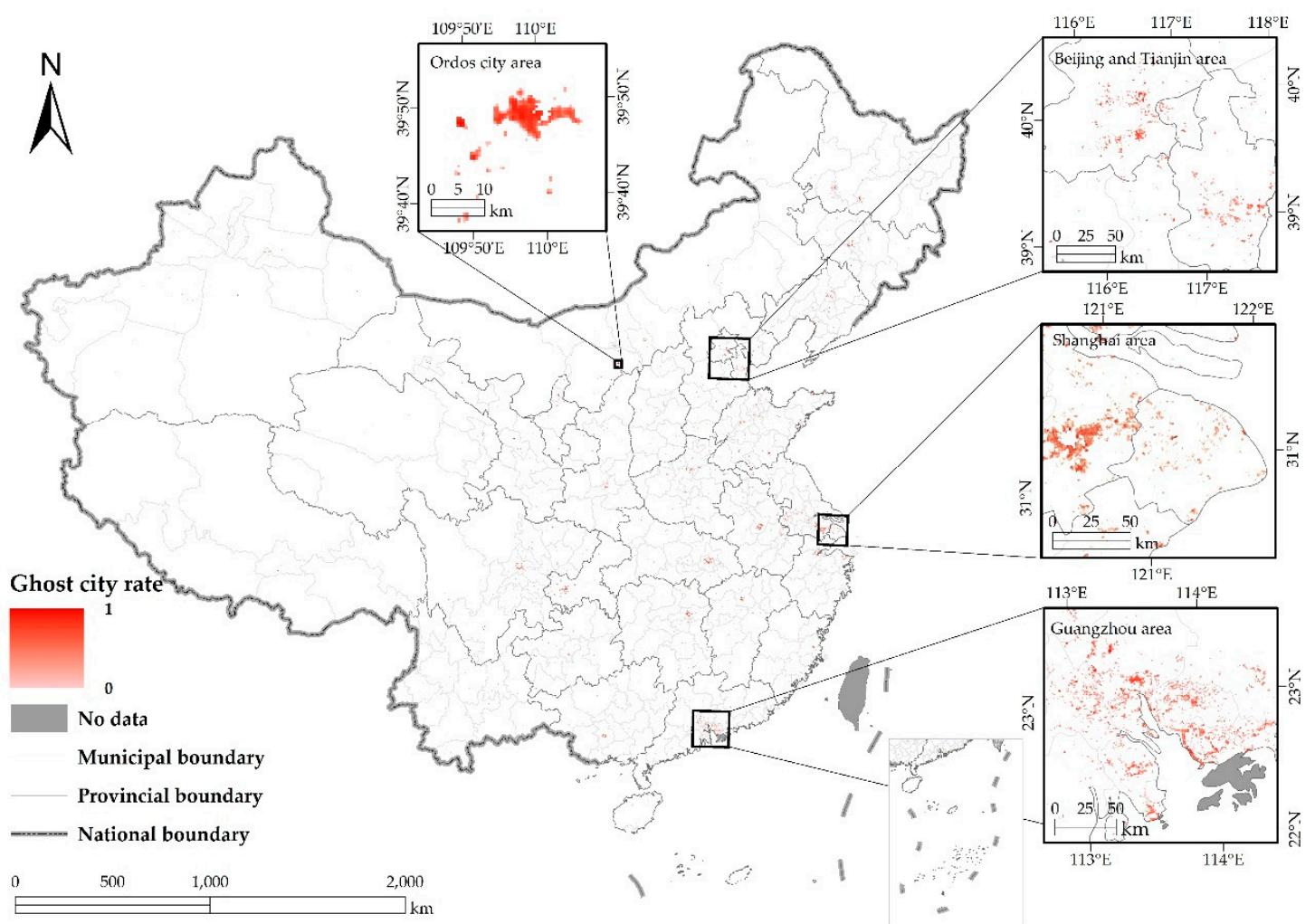

Figure 3. Spatial distribution of China's ghost city rate in 2013. The four regions are magnified and shown in detail.

Four cities were selected to show the changes from NTL to GCR in the extraction process. The results are shown in Figure 4. In Harbin, the capital city of Heilongjiang Province, the AGCR was $52.32 \%$. In Changchun, the capital city of Jilin Province, the AGCR was 55.28\%. In Shanghai, one of China's four municipalities, the provincial AGCR was $21.75 \%$. In Changsha, the capital city of Hunan Province, the AGCR was $40.12 \%$. 

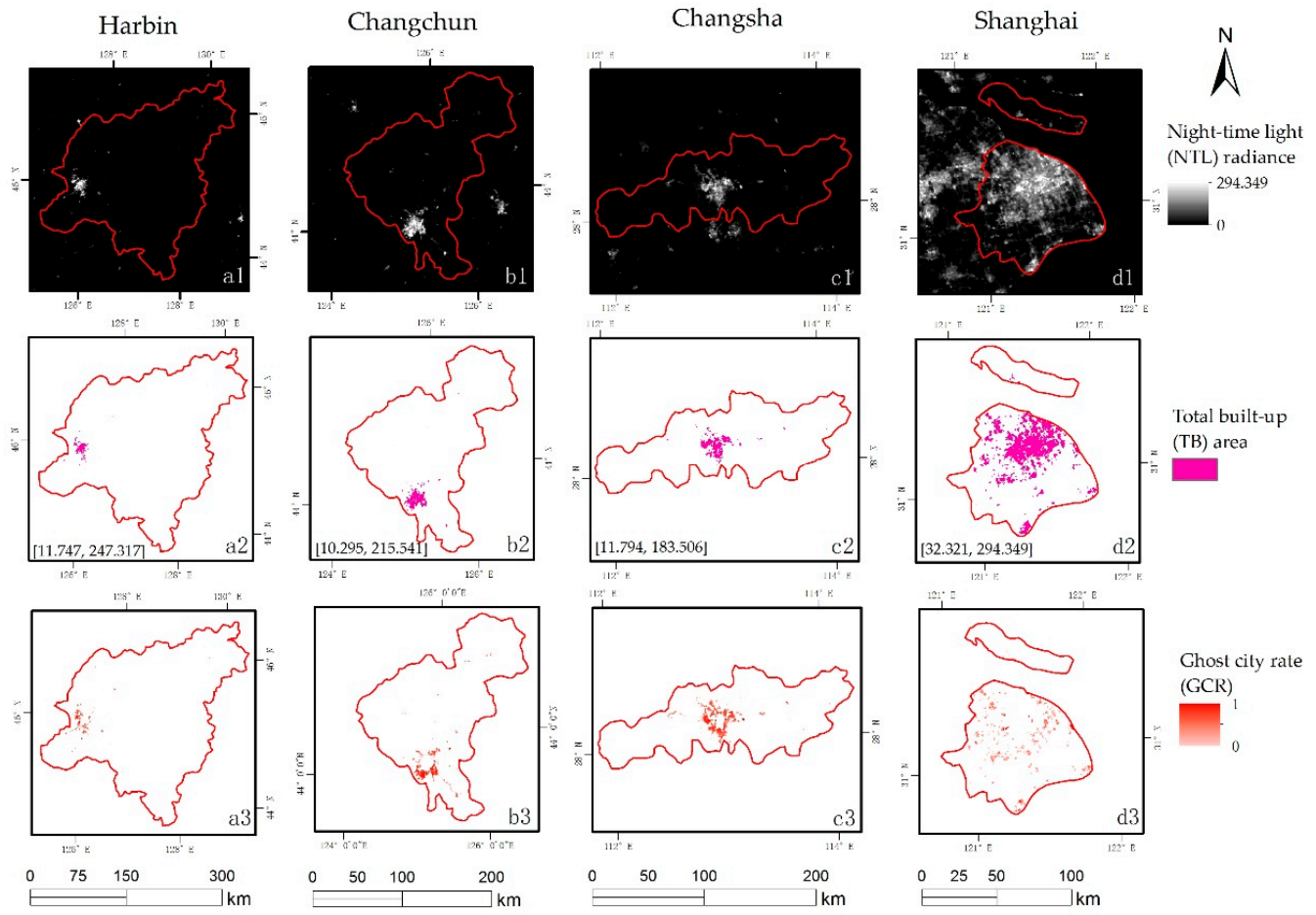

Figure 4. Four different spatial distributions of the estimated night-time light (NTL), total built-up (TB) area and ghost city rate (GCR) in four typical cities. The $\mathbf{a 1}, \mathbf{b} \mathbf{1}, \mathbf{c 1}$ and $\mathbf{d} \mathbf{1}$ are the NPP-VIIRS night-time light radiance; a2, b2, c2, and $\mathbf{d} 2$ are the total built-up areas and the optimal threshold; a3, b3, c3, and $\mathbf{d} \mathbf{3}$ are ghost city rate imagery. The red lines in figures are the municipal administrative boundaries.

\subsection{Provincial Average Ghost City Rate and Correlation Analysis}

Using Equation (2), the AGCR of 31 provincial administrative regions were calculated (Table 2). Provinces with a high AGCR were Jilin, Heilongjiang, Inner Mongolia and Tibet. The regions with AGCRs less than 30\% included Shanghai, Tianjin, Jiangsu, Guangdong, Hainan and Beijing. The lowest AGCR was found in Shanghai, only $21.71 \%$.

Table 2. AGCR of China and 31 provincial administrative regions.

\begin{tabular}{cccccc}
\hline ID & Region Name & AGCR (\%) & ID & Region Name & AGCR (\%) \\
\hline 1 & China & 35.1 & 17 & Jiangsu & 29.81 \\
2 & Anhui & 35.04 & 18 & Jiangxi & 36.7 \\
3 & Beijing & 32.07 & 19 & Liaoning & 38.01 \\
4 & Chongqing & 38.44 & 20 & Inner Mongolia & 42.06 \\
5 & Fujian & 30.35 & 21 & Ningxia & 37.89 \\
6 & Gansu & 36.92 & 22 & Qinghai & 34.2 \\
7 & Guangdong & 29.91 & 23 & Shandong & 34.57 \\
8 & Guangxi & 36.84 & 24 & Shanxi & 34.92 \\
9 & Guizhou & 34.05 & 25 & Shaanxi & 34.26 \\
10 & Hainan & 28.1 & 26 & Shanghai & 21.71 \\
11 & Hebei & 35.55 & 27 & Sichuan & 33.09 \\
12 & Henan & 34.74 & 28 & Tianjin & 28.06 \\
13 & Heilongjiang & 46.76 & 29 & Tibet & 40.01 \\
14 & Hubei & 36.18 & 30 & Xinjiang & 37.45 \\
15 & Hunan & 38.29 & 31 & Yunnan & 33.41 \\
16 & Jilin & 47.27 & 32 & Zhejiang & 30.13 \\
\hline
\end{tabular}


The results indicated that there were significant negative correlations between the provincial AGCR and two indicators (Figure 5). The first indicator was the per capita disposable income of urban households. The second indicator was the average selling price of commercialized buildings. The Pearson correlation coefficients were $-0.659(p<0.01)$ for the provincial AGCR and per capita disposable income of urban households and $-0.637(p<0.01)$ for the provincial AGCR and the average selling price of commercial buildings.
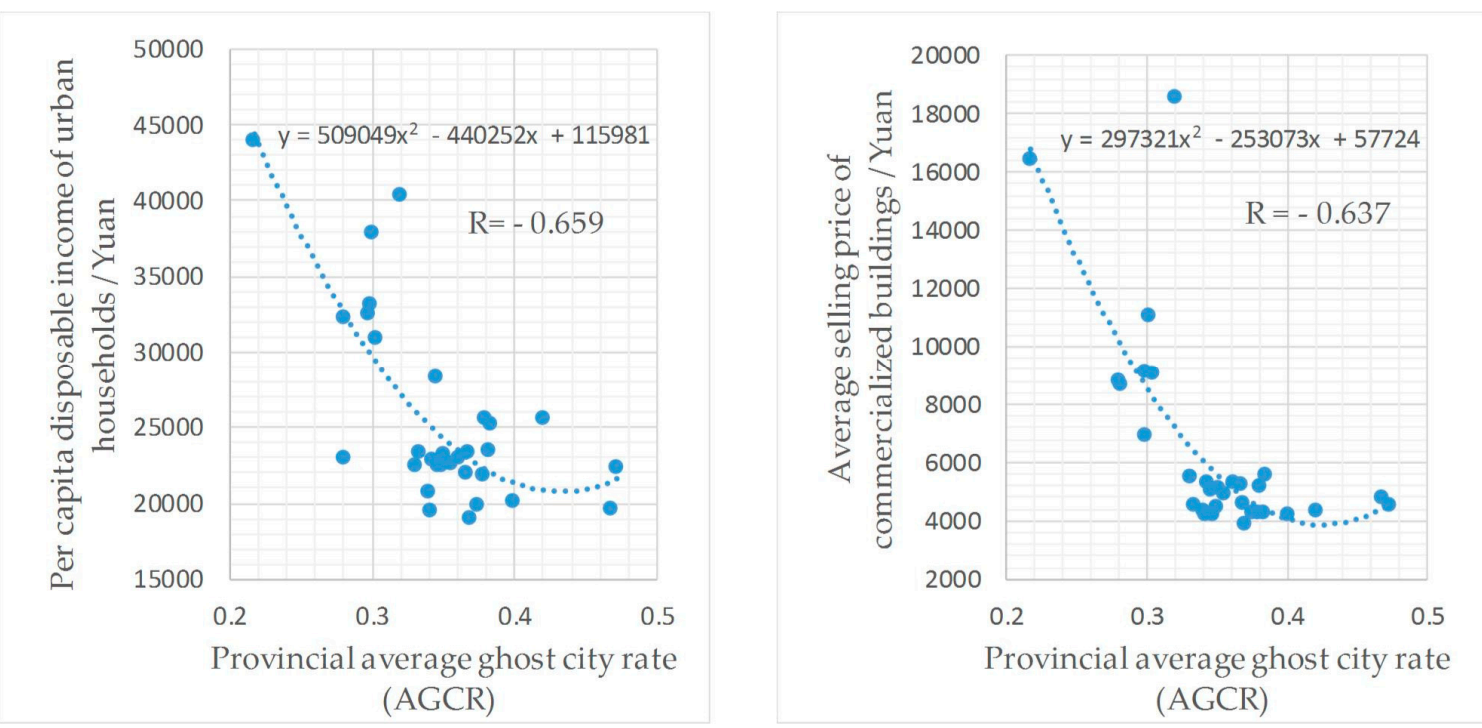

Figure 5. The scatter plots between 31 provincial AGCRs with the per capita disposable income of urban households and the average selling price of commercial buildings in China.

\subsection{Ghost City Extraction}

To extract the ghost cities, 333 municipal AGCRs were analyzed, with the municipal administrative region as the basic unit for the comparative analysis. The 333 municipal AGCRs fit a normal distribution (Figure 6) and one-third of China's municipal regions had an AGCR between 30 and 35\%. Thus it is appropriate to categorize municipal AGCRs using the standard deviation classification [49]. The AGCR of these cities was divided into five grades using the standard division classification method (Table 3). According to the seriousness of the municipal AGCR, ghost cities were defined as those cities whose municipal AGCRs were in category V. In total, 31 ghost cities were extracted.

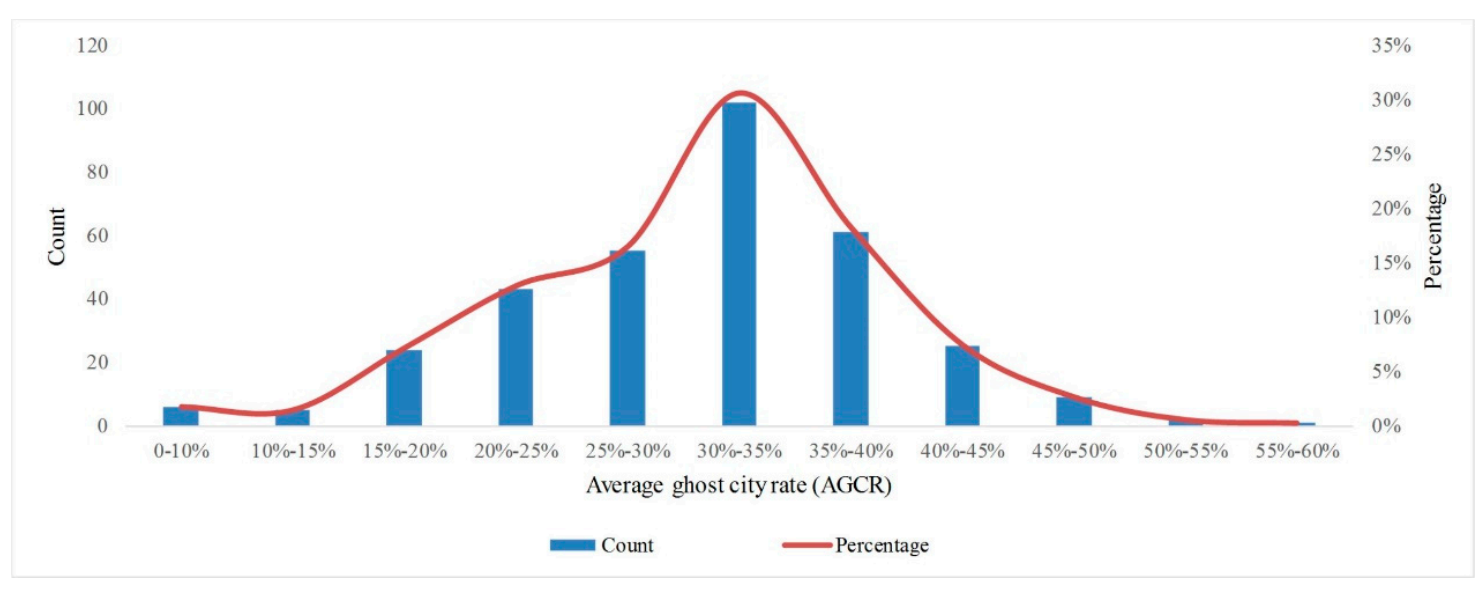

Figure 6. Normal distribution of municipal AGCRs. 
Table 3. The AGCR classification by the standard deviation (STD) method. The AGCR is the average ghost city rate; AGCRi is the AGCR of the ith municipal region; AGCRmax and AGCRmin are the maximum and minimum municipal AGCR values, respectively; $\mathrm{m}$ is the mean; and std is the standard deviation of the 333 municipal AGCRs in China.

\begin{tabular}{ccccc}
\hline AGCR Category & Division Standard & Result of Division & Count & Percentage \\
\hline I & AGCRmin $\leq \mathrm{AGCRi}<\mathrm{m}-$ std & $0 \leq \mathrm{AGCRi}<22.56 \%$ & 38 & $11.41 \%$ \\
II & $\mathrm{m}-$ std $\leq \mathrm{AGCRi}<\mathrm{m}-0.5 \mathrm{std}$ & $22.56 \% \leq \mathrm{AGCRi}<26.97 \%$ & 41 & $12.31 \%$ \\
III & $\mathrm{m}-0.5 \mathrm{std} \leq \mathrm{AGCRi}<\mathrm{m}+0.5 \mathrm{std}$ & $26.97 \% \leq \mathrm{AGCRi}<35.78 \%$ & 164 & $49.25 \%$ \\
IV & $\mathrm{m}+0.5 \mathrm{std} \leq \mathrm{AGCRi}<\mathrm{m}+\mathrm{std}$ & $35.78 \% \leq \mathrm{AGCRi}<40.18 \%$ & 59 & $17.72 \%$ \\
V & $\mathrm{m}+\mathrm{std} \leq \mathrm{AGCRi} \leq \mathrm{AGCRmax}$ & $40.18 \% \leq \mathrm{AGCRi} \leq 55.35 \%$ & 31 & $9.31 \%$ \\
\hline
\end{tabular}

\subsection{Accuracy Check}

As shown in Table 4, according to the accuracy check of the above five cities, despite the differences between provincial and municipal scales, the ghost city categories remain consistent. The municipal AGCR of categories IV and V, for example Hohhot and Xi'an, were overestimated, where the municipal AGCR of categories I and III, for example Songyuan, Hengyang and Hangzhou, were slightly underestimated. Thus, the cities with low municipal AGCRs may have a more serious ghost city phenomenon. The municipal AGCR of category V showed a very small difference $(0.06 \%)$, the difference was too small to influence the ghost city extraction. Thus, our ghost city extraction method is effective when using the provincial-level built-up area statistical data.

Table 4. The difference between the municipal AGCR estimate results using provincial and municipal built-up area statistical data.

\begin{tabular}{cccccc}
\hline \multirow{2}{*}{ Validation City } & \multicolumn{2}{c}{$\begin{array}{c}\text { Using Provincial Built-Up Area } \\
\text { Statistical Data }\end{array}$} & \multicolumn{2}{c}{$\begin{array}{c}\text { Using Municipal Built-Up Area } \\
\text { Statistical Data }\end{array}$} & \multirow{2}{*}{ Difference (\%) } \\
\cline { 2 - 5 } & Municipal AGCR (\%) & Category & Municipal AGCR (\%) & Category & \\
\hline Hohhot & 40.25 & V & 40.19 & V & 0.06 \\
Xi'an & 36.6 & IV & 35.81 & IV & 0.79 \\
Songyuan & 33.09 & III & 33.27 & III & -0.18 \\
Hengyang & 28.12 & III & 30.79 & III & -2.67 \\
Hanzhong & 15.79 & I & 18.95 & I & -3.16 \\
\hline
\end{tabular}

At present, there is neither a widely accepted ghost city extraction method nor officially-released statistics for China. Due to the lack of available ghost city validation datasets, ghost city validation work is often controversial. Nonetheless, in this research, strong efforts were made to compare the results with third party institutions, existing papers and media publications to improve the extraction accuracy of ghost cities in China.

As addressed in the "Introduction", the housing vacancy rate is one of the most important indicators for assessing the inhabitant quantity and urban vacancy phenomenon. The CHFS carried out a sampling survey on the housing vacancy rate across the 29 provinces, 262 counties and 1048 communities in China [13]. They found, on the national scale, that the housing vacancy rates in the central and western regions were higher than those in the eastern region. On the city scale, the housing vacancy rates of undeveloped cities were greater than those of the developed cities. According to a detailed analysis of six cities including Beijing, Shanghai, Chongqing, Chengdu, Wuhan, and Tianjin, the city with the highest vacancy rates was Chongqing. This is consistent with our results. For instance, as shown in Figure 6, the ghost cities were mainly concentrated in the economically undeveloped inland region, and the municipal AGCR of Chongqing (38.44\%) was greater than others municipal cities (Beijing of $32.07 \%$ and Shanghai of $21.71 \%$ ). Moreover, compared with the ghost city extraction results in previous studies and media reports (Appendix A), most of the previous results showed that the majority of ghost cities were located in the inland border areas of China, which are consistent 
with our results. Overall, our results using the new effective method are basically consistent with published results.

\section{Discussion}

\subsection{Correlation Analysis on the Provincial Scale}

To analyze how the ghost city phenomenon emerged during rapid urbanization in China, a correlation analysis between the provincial AGCR and two indicators was employed. The per capita disposable income of urban households is representative of a resident's purchasing power. The average selling price of commercialized buildings, calculated by dividing the total price of all commercial buildings by the total area, is an important price index in the real estate market. The results showed some useful information, indicating that regions where the residents have weak purchasing power and where there are low housing prices always have a serious ghost city phenomenon. Areas with high AGCRs are concentrated in the border areas in northeast, northwest and southwest China (Figure 7) and the AGCR in the southeastern coastal areas is relatively low. The difference in AGCR from the southeast coast to the northwest inland regions was similar to the regional differences in economic development. During urban expansion, the levels of urbanization are closely correlated to levels of economic development [38]. In general, the income level of urban residents and housing prices are determined by the level of a city's economic development, which is the result of long-term development.

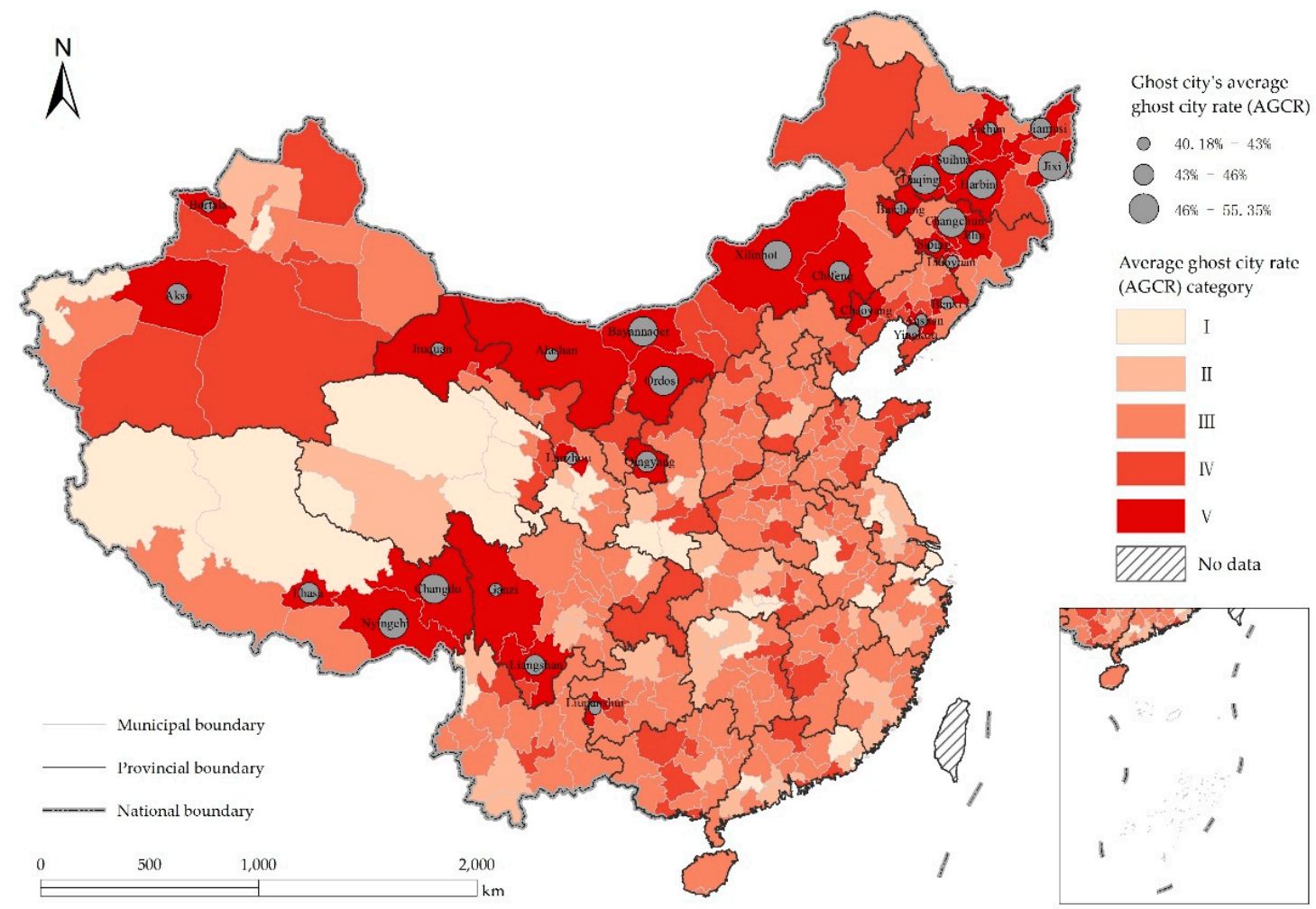

Figure 7. The spatial distribution of China's municipal AGCRs. The five categories of municipal AGCR are shown in the different colors. The 31 ghost cities are labeled with a gray circle with three categories.

\subsection{Spatial Pattern of Ghost City Areas}

Eight typical ghost cities (Figure 8) in the eastern (D, J, H, C), central $(\mathrm{O}, \mathrm{X})$ and western $(\mathrm{B}, \mathrm{N})$ regions were selected for comparison. By comparing these typical ghost cities, we could see that the ghost city areas in different cities have their own spatial patterns. Ghost city areas in the developed 
eastern coastal cities were more dispersed, showing a round or ring shape, while in undeveloped central and western areas, ghost city areas were aggregated, showing an oval shape.

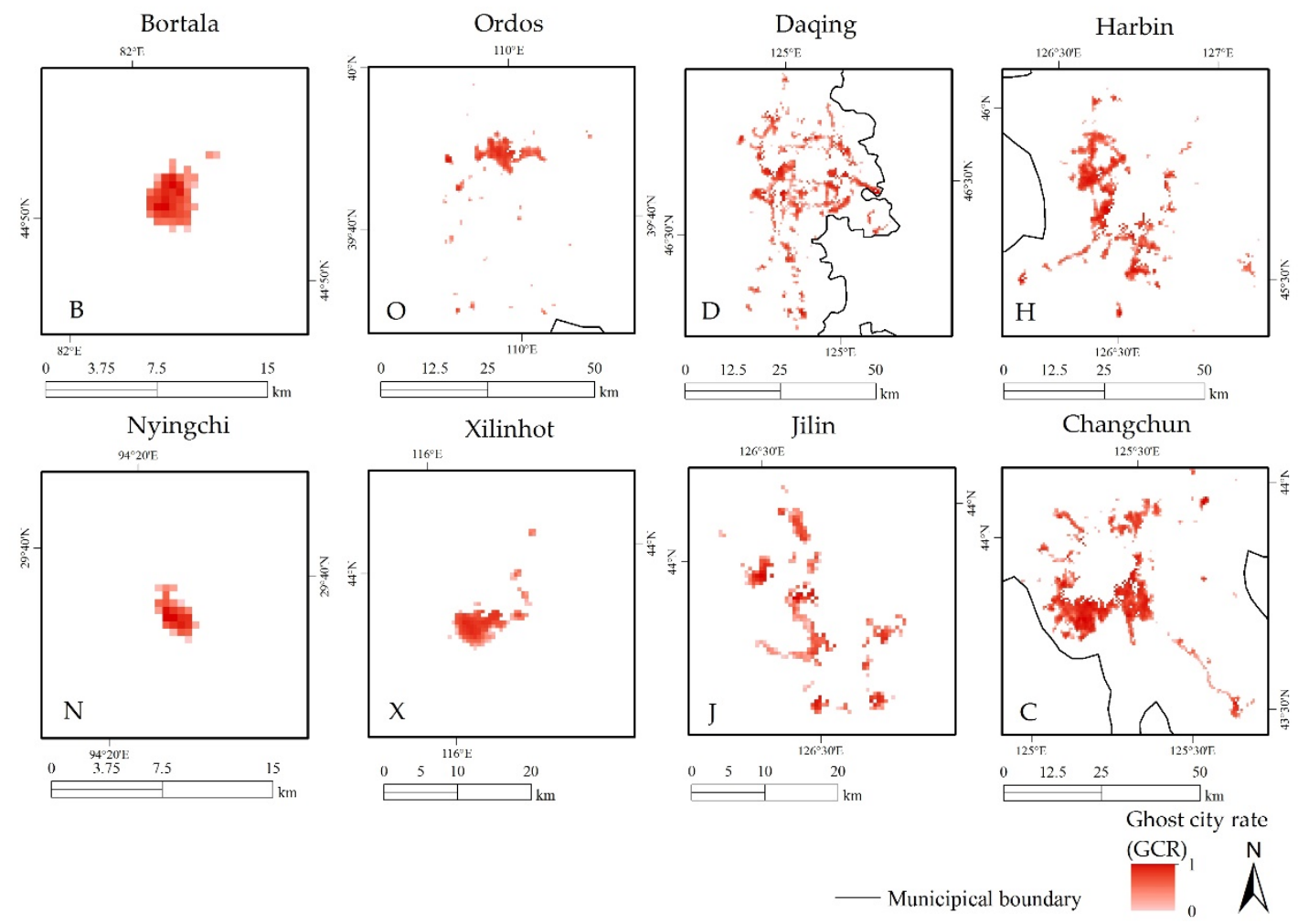

Figure 8. Different spatial patterns of eight ghost cities, four in eastern China (D, Daqing, AGCR is $46.22 \%$; J, Jilin, AGCR is $40.9 \%$; $\mathrm{H}$, Harbin, AGCR is $52.23 \%$; C, Changchun, AGCR is $55.35 \%$ ), two in central China (O, Ordos, AGR is 47.16\%; X, Xilinhot, AGCR is 46.94\%), and two in western China (B, Bortala, AGCR is $41.32 \%$; N, Nyingchi, AGCR is $47.26 \%$ ); and the black lines in the figures are the municipal administrative boundaries.

Some characteristics were observed in the spatial distribution of ghost city areas. The ghost city areas were located on the edges of the built-up areas (Figure 4). In general, the cities' central areas had well-developed infrastructure, a fast-moving and convenient traffic system, and a high population; however, the edges of the urban built-up areas lacked these supportive conditions [6]. The ghost city phenomenon that emerged during the rapid urbanization is due to the urban population growth lagging behind the development of urban land in extreme cases, resulting in few or no people living in the new built-up areas. On the one hand, it is hard to expand a city with a small population and low economic development power; on the other hand, the attraction to such a city is weak and cannot fill the ghost city area's population vacancy.

In the process of urban development and construction, the expansion of built-up areas is an inevitable process. However, in this process, policy guidance by the local government plays an important role [50,51]. As we mentioned, the ghost city areas are located on the edges of a city's built-up areas. These areas represent the direction of urban expansion. Thus, these areas were usually planned as new development areas in urban planning. However, unrealistic urban planning policy is likely to produce a ghost city phenomenon in the urban new areas, such as Ordos.

\section{Conclusions}

In this study, the ghost city rate (GCR) and average ghost city rate (AGCR) were analyzed to quantify the severity of the ghost city problem using night-time light data. Compared with media 
reports and other studies on ghost cities, this method combines statistical data with the distribution of vacant urban areas, and provides a visual approach to help residents, officials and urban planners to understand the spatial distribution of ghost cities. After the accuracy check, this method can be considered as an effective method to capture the ghost city information. The results of this study show that China's average AGCR was 35.1\% in 2013. More than one-third of China's urban built-up areas have varying degrees of vacancy.

Correlation analyses were conducted for the relationship between provincial AGCRs and two indicators (the per capita disposable income of urban households and the average selling price of commercial buildings). The Pearson correlation coefficients were $-0.659(p<0.01)$ and $-0.637(p<0.01)$, respectively, indicating that regions where the residents have weak purchasing power and low housing prices often have a serious ghost city phenomenon. The result also provides a risk assessment for the government to establish urban planning policy. Cities where the residents have weak purchasing power and where there are low housing prices should be more careful with urban planning and policymaking.

At the municipal scale, the vast majority of cities in China have ghost city areas, with AGCRs ranging from 30 to $35 \%$. Using the municipal AGCR, 31 ghost cities were extracted. These ghost cities were mainly concentrated in the economically underdeveloped inland provinces, such as Heilongjiang, Inner Mongolia, and Xinjiang.

Regarding the spatial distribution, the ghost city areas were concentrated along the edges of the urban built-up areas. The spatial pattern of ghost city areas was different in the different regions of China. The ghost city areas in the developed regions of eastern coastal China were dispersed, while they were more aggregated in the western undeveloped regions.

Considering the limitation of the validation data, it is valuable to further improve the evaluation framework by using multi-source data, such as point of interest, location-based service data and high spatial resolution nighttime light imagery.

Author Contributions: W.G., H.Y. and M.M. conceived and designed the experiments; W.G. performed the experiments and analyzed the data; W.G., H.Y., X.Z., M.M. and Y.Y. jointly revised the paper.

Acknowledgments: This study was supported by the National Key Technology R\&D Program of China (grant number: 2016YFC0500106), Special Project of Science and Technology Basic Work (grant number: 2014FY210800-5), the National Natural Science Foundation of China (41771453), the Open Research Fund Program of Chongqing Engineering Research Center for Remote Sensing Big Data Application, and Open Research Fund Program of Chongqing Key Laboratory of Karst Environment, Southwest University.

Conflicts of Interest: The authors declare no conflict of interest.

\section{Appendix A. List of Ghost Cities in China}

\begin{tabular}{|c|c|c|c|}
\hline This Study, 2013 & Standard Ranking, 2015 & Baidu Big Data Lab, 2015 & NetEase Property, 2013 \\
\hline Changchun (Jilin) & Erlianhaote (Inner Mongolia) & Ordos (Inner Mongolia) & Ordos (Inner Mongolia) \\
\hline Harbin (Heilongjiang) & Alar (Xinjiang) & Tongliao (Inner Mongolia) & Hohhot (Inner Mongolia) \\
\hline Suihua (Heilongjiang) & Beitun (Xinjiang) & Shenyang (Liaoning) & Bayannaoer (Inner Mongolia) \\
\hline Changdu (Tibet) & Altay (Xinjiang) & Changchun (Jilin) & Erlianhaote (Inner Mongolia) \\
\hline Jixi (Heilongjiang) & Zhangye (Gansu) & Hohhot (Inner Mongolia) & Zhengzhou (Henan) \\
\hline Bayannaoer (Inner Mongolia) & Suifenhe (Heilongjiang) & Weihai (Shandong) & Hebi (Henan) \\
\hline Xilinhot (Inner Mongolia) & Yumen (Gansu) & Dongying (Shandong) & Changzhou (Jiangsu) \\
\hline Daqing (Heilongjiang) & Shigatse (Tibet) & Taizhou (Jiangsu) & Zhenjiang (Jiangsu) \\
\hline Aksu (Xinjiang) & Golmud (Qinghai) & Changshu (Jiangsu) & Shiyan (Hubei) \\
\hline Chifeng (Inner Mongolia) & Ruili (Yunnan) & Jinnan District (Tianjin) & Chenggong (Yunnan) \\
\hline Qingyang (Gansu) & Turpan (Xinjiang) & Chengdu (Sichuan) & \\
\hline Anshan (Liaoning) & Yichun (Heilongjiang) & Hangzhou (Zhejiang) & \\
\hline Liaoyuan (Jilin) & Shizuishan (Ningxia) & Qiongzhou (Hainan) & \\
\hline Jiuquan (Gansu) & Xilinhaote (Inner Mongolia) & & \\
\hline Baicheng (Jilin) & Jinchang (Gansu) & & \\
\hline
\end{tabular}




\begin{tabular}{ll}
\hline Yichun (Heilongjiang) & Fangchenggang (Guangxi) \\
Benxi (Liaoning) & Dehui (Jilin) \\
Yingkou (Liaoning) & Donggang (Liaoning) \\
Chaoyang (Liaoning) & Shulan (Jilin) \\
Bortala (Xinjiang) & Kuerle (Xinjiang) \\
Lanzhou (Gansu) & Ordos (Inner Mongolia) \\
Jilin (Jilin) & Hulunbeier (Inner Mongolia) \\
Siping (Jilin) & Lhasa (Tibet) \\
Ganzi (Sichuan) & Huolinguole (Inner Mongolia) \\
Liupanshui (Guizhou) & Weihai (Shandong) \\
Alashan (Inner Mongolia) & Changshu (Jiangsu) \\
\hline
\end{tabular}

\section{References}

1. Chen, M. Evolution and assessment on China's urbanization 1960-2010: Under-urbanization or over-urbanization? Habitat Int. 2013, 38, 25-33. [CrossRef]

2. Bai, X.; Shi, P.; Liu, Y. Realizing China's urban dream. Nature 2014, 509, 158-160. [CrossRef] [PubMed]

3. Liu, Y.; Huang, X.; Yang, H.; Zhong, T. Environmental effects of land-use/cover change caused by urbanization and policies in southwest China karst area-A case study of Guiyang. Habitat Int. 2014, 44, 339-348. [CrossRef]

4. Yang, H.; Huang, X.; Thompson, J.R.; Bright, R.M.; Astrup, R. The crushing weight of urban waste. Science 2016, 351, 674. [CrossRef] [PubMed]

5. Yang, H.; Huang, X.; Thompson, J.R.; Flower, R.J. Soil pollution: Urban brownfield. Science 2014, 344, 691-692. [CrossRef] [PubMed]

6. He, G.; Mol, A.P.J.; Lu, Y. Wasted cities in urbanizing China. Environ. Dev. 2016, 18, 2-13. [CrossRef]

7. Jin, X.; Long, Y.; Sun, W.; Lu, Y.; Yang, X.; Tang, J. Evaluating cities' vitality and identifying ghost cities in China with emerging geographical data. Cities 2017, 63, 98-109. [CrossRef]

8. Zheng, Q.; Zeng, Y.; Deng, J.; Wang, K.; Jiang, R.; Ye, Z. “Ghost cities” identification using multi-source remote sensing datasets: A case study in Yangtze river delta. Appl. Geogr. 2017, 80, 112-121. [CrossRef]

9. Ordos, China: A Modern Ghost Town. Available online: http://content.time.com/time/photogallery/0, 29307,1975397,00.html (accessed on 8 November 2016).

10. Shepard, W. Ghost Cities of China; Zed Books: London, UK, 2015.

11. Zhang, L.; Zhao, S.X. Reinterpretation of China's under-urbanization: A systemic perspective. Habitat Int. 2003, 27, 459-483. [CrossRef]

12. Chi, G.; Liu, Y.; Wu, Z.; Wu, H. Ghost cities analysis based on positioning data in China. Comput. Sci. 2015, $68,1150-1156$.

13. Urban Housing Vacancy Rate and Housing Market Development Trend. Available online: http://chfs.swufe. edu.cn/xiangqing.aspx?id=900 (accessed on 16 November 2016).

14. Yao, Y.; Li, Y. House vacancy at urban areas in China with nocturnal light data of DMSP-OLS. In Proceedings of the 2011 IEEE International Conference on Spatial Data Mining and Geographical Knowledge Services, Fuzhou, China, 29 June-1 July 2011; pp. 457-462.

15. Chen, Z.; Yu, B.; Hu, Y.; Huang, C.; Shi, K.; Wu, J. Estimating house vacancy rate in metropolitan areas using npp-viirs nighttime light composite data. IEEE J. Sel. Top. Appl. Earth Obs. Remote Sens. 2017, 8, 2188-2197. [CrossRef]

16. Wang, H.; Chang, C.J. Simulation of housing market dynamics: Amenity distribution and housing vacancy. In Proceedings of the 2013 Winter Simulations Conference (WSC), Washington, DC, USA, 8-11 December 2013; pp. 1673-1684.

17. Elvidge, C.D.; Baugh, K.E.; Kihn, E.A.; Kroehl, H.W.; Davis, E.R.; Davis, C.W. Relation between satellite observed visible-near infrared emissions, population, economic activity and electric power consumption. Int. J. Remote Sens. 1997, 18, 1373-1379. [CrossRef]

18. Keola, S.; Andersson, M.; Hall, O. Monitoring economic development from space: Using nighttime light and land cover data to measure economic growth. World Dev. 2015, 66, 322-334. [CrossRef]

19. Wang, X.; Ma, M. The luminous intensity of regional 'night-light' output can predict the growing volume of published scientific research by 'luminaries' in developing countries. Scientometrics 2016, 110, 1-6. [CrossRef] 
20. He, C.; Shi, P.; Li, J.; Chen, J.; Pan, Y.; Li, J.; Li, Z.; Ichinose, T. Restoring urbanization process in China in the 1990s by using non-radiance-calibrated DMSP/OLS nighttime light imagery and statistical data. Chin. Sci. Bull. 2006, 51, 1614-1620. [CrossRef]

21. Sutton, P.; Roberts, D.; Elvidge, C.; Melj, H. A comparison of nighttime satellite imagery and population density for the continental united states. Photogramm. Eng. Remote Sens. 1997, 63, 1303-1313.

22. Yang, X.; Yue, W.; Gao, D. Spatial improvement of human population distribution based on multi-sensor remote-sensing data: An input for exposure assessment. Int. J. Remote Sens. 2013, 34, 5569-5583. [CrossRef]

23. Zeng, C.; Zhou, Y.; Wang, S.; Yan, F.; Zhao, Q. Population spatialization in China based on night-time imagery and land use data. Int. J. Remote Sens. 2011, 32, 9599-9620. [CrossRef]

24. Bharti, N.; Tatem, A.J.; Ferrari, M.J.; Grais, R.F.; Djibo, A.; Grenfell, B.T. Explaining seasonal fluctuations of measles in Niger using nighttime lights imagery. Science 2011, 334, 1424-1427. [CrossRef] [PubMed]

25. Kohiyama, M.; Hayashi, H.; Maki, N.; Higashida, M.; Kroehl, H.W.; Elvidge, C.D.; Hobson, V.R. Early damaged area estimation system using DMSP-OLS night-time imagery. Int. J. Remote Sens. 2004, 25, 2015-2036. [CrossRef]

26. Liu, Z. Modeling the spatiotemporal dynamics of electric power consumption in mainland China using saturation-corrected DMSP/OLS nighttime stable light data. Int. J. Digit. Earth 2014, 7, 993-1014.

27. Shi, K.; Huang, C.; Yu, B.; Yin, B.; Huang, Y.; Wu, J. Evaluation of NPP-VIIRS night-time light composite data for extracting built-up urban areas. Remote Sens. Lett. 2014, 5, 358-366. [CrossRef]

28. Deren, L.I.; Xi, L.I. An overview on data mining of nighttime light remote sensing. Acta Geod. Et Cartogr. Sin. 2015, 44, 591-601.

29. Small, C.; Elvidge, C.D.; Balk, D.; Montgomery, M. Spatial scaling of stable night lights. Remote Sens. Environ. 2011, 115, 269-280. [CrossRef]

30. Small, C.; Pozzi, F.; Elvidge, C.D. Spatial analysis of global urban extent from DMSP-OLS night lights. Remote Sens. Environ. 2005, 96, 277-291. [CrossRef]

31. Yang, Y. Timely and accurate national-scale mapping of urban land in China using defense meteorological satellite program's operational linescan system nighttime stable light data. J. Appl. Remote Sens. 2013, 7, 073535. [CrossRef]

32. Yang, Y.; He, C.; Zhao, Y.; Li, T. Research on the layered threshold method for extracting urban land using the DMSP/OLS stable nighttime light data. J. Image Graph. 2011, 16, 666-673.

33. NOAA's National Centers for Environmental Information Earth Observation Group. Available online: http:/ / www.ngdc.noaa.gov /eog/viirs/download_dnb_composites.html (accessed on 11 November 2016).

34. Elvidge, C.D.; Baugh, K.; Zhizhin, M.; Feng, C.H.; Ghosh, T. VIIRS night-time lights. Int. J. Remote Sens. 2017, 1, 1-20. [CrossRef]

35. Yi'na, H.; Peng, J.; Liu, Y.; Du, Y.; Li, H. Mapping Development Pattern in Beijing-Tianjin-Hebei Urban Agglomeration Using DMSP/OLS Nighttime Light Data. Remote Sens. 2017, 9, 760. [CrossRef]

36. Zhang, L.; Zhang, L.; Peng, J.; Liu, Y.; Wu, J. Coupling ecosystem services supply and human ecological demand to identify landscape ecological security pattern: A case study in Beijing-Tianjin-Hebei region, China. Urban Ecosyst. 2017, 20, 701-714. [CrossRef]

37. Ma, L.; Wu, J.; Li, W.; Peng, J.; Liu, H. Evaluating Saturation Correction Methods for DMSP/OLS Nighttime Light Data: A Case Study from China's Cities. Remote Sens. 2014, 6, 9853-9872. [CrossRef]

38. Elvidge, C.D.; Baugh, K.E.; Zhizhin, M.; Hsu, F.C. Why VIIRS data are superior to DMSP for mapping nighttime lights. Proc. Asia-Pac. Adv. Netw. 2013, 35, 62-69. [CrossRef]

39. NASA's Earth Observing System Data and Information System. Available online: http:/ / reverb.echo.nasa. gov/reverb / (accessed on 25 November 2016).

40. National Bureau of Statistics of the People's Republic of China. Available online: http://www.stats.gov.cn/ tjsj/ndsj/2014/indexch.htm (accessed on 25 November 2016).

41. Ma, T.; Zhou, C.; Tao, P.; Haynie, S.; Fan, J. Responses of Suomi-NPP VIIRS-derived nighttime lights to socioeconomic activity in China's cities. Remote Sens. Lett. 2014, 5, 165-174. [CrossRef]

42. Shu, S.; Bai-Lang, Y.U.; Jian-Ping, W.U.; Liu, H.X. Methods for deriving urban built-up area using night-light data: Assessment and application. Remote Sens. Technol. Appl. 2011, 26, 169-176.

43. Lu, D.; Tian, H.; Zhou, G.; Ge, H. Regional mapping of human settlements in southeastern China with multisensor remotely sensed data. Remote Sens. Environ. 2008, 112, 3668-3679. [CrossRef] 
44. Pandey, B.; Joshi, P.K.; Seto, K.C. Monitoring urbanization dynamics in India using DMSP/OLS night time lights and SPOT-VGT data. Int. J. Appl. Earth Obs. Geoinf. 2013, 23, 49-61. [CrossRef]

45. Elvidge, C.D. Mapping city lights with nighttime data from the DMSP operational linescan system, photogramm. Eng. Remote Sens. 1997, 63, 727-734.

46. Imhoff, M.L.; Lawrence, W.T.; Stutzer, D.C.; Elvidge, C.D. A technique for using composite DMSP/OLS “city lights" satellite data to map urban area. Remote Sens. Environ. 1997, 61, 361-370. [CrossRef]

47. Henderson, M.; Yeh, E.T.; Gong, P.; Elvidge, C.; Baugh, K. Validation of urban boundaries derived from global night-time satellite imagery. Int. J. Remote Sens. 2003, 24, 595-609. [CrossRef]

48. Cao, X.; Chen, J.; Imura, H.; Higashi, O. A SVM-based method to extract urban areas from DMSP-OLS and spot VGT data. Remote Sens. Environ. 2009, 113, 2205-2209. [CrossRef]

49. Quan, J.; Chen, Y.; Zhan, W.; Wang, J.; Voogt, J. Multi-temporal trajectory of the urban heat island centroid in Beijing, China based on a Gaussian volume model. Remote Sens. Environ. 2014, 149, 33-46. [CrossRef]

50. Yang, H. China must continue the momentum of green law. Nature 2014, 509, 535. [CrossRef] [PubMed]

51. Yang, H.; Huang, X.; Thompson, J.R.; Flower, R.J. Enforcement key to China's environment. Science 2015, 347, 834-835. [CrossRef] [PubMed]

(C) 2018 by the authors. Licensee MDPI, Basel, Switzerland. This article is an open access article distributed under the terms and conditions of the Creative Commons Attribution (CC BY) license (http://creativecommons.org/licenses/by/4.0/). 